\title{
Marked foreign body reaction and thrombus formation after transcatheter closure of a patent foramen ovale
}

\author{
Herwig W. Schuchlenz, MD, ${ }^{a}$ Sebastian Mannweiler, MD, ${ }^{\mathrm{b}}$ and Daniela Martin, MD, ${ }^{\mathrm{c}} \mathrm{Graz}$, Austria
}

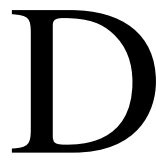
espite the lack of consensus regarding the optimal management strategy after a presumed paradoxic embolism through a patent foramen ovale (PFO), percutaneous device closure is used frequently for secondary prevention in these patients. ${ }^{1,2}$ This report describes the first histologically proven case of a symptomatic device thrombosis as a result of a chronic inflammatory foreign body response to a PFO closure device.

\section{Clinical Summary}

A 48-year-old woman presented to the emergency department with signs of a completed stroke. Five hours before admission, hemihypesthesia and weakness developed on her right side. She had received a percutaneous occlusion (28-mm CardioSEAL device; NMT Medical, Boston, Mass) of her PFO after a cryptogenic cerebrovascular event 2 months earlier. She was discharged and prescribed Aspirin (100 mg once daily) the day after the intervention. Laboratory tests for hypercoagulable states showed normal results during the first evaluation and on readmittance. Neither diffusion-weighted magnetic resonance imaging of the brain nor ultrasound examination of the brain supplying arteries revealed pathologic findings. An urgent transesophageal echocardiographic study demonstrated 2 large pedunculated thrombi on the left atrial disk of the CardioSEAL device (Figure 1). An electrocardiogram showed ectopic atrial beats. The patient was first administered Clopidogrel $(75 \mathrm{mg})$ and low-molecular heparin (80 mg enoxaparin twice/day). After 10 days she was readmitted with the same symptoms. The transesophageal echocardiogram documented the known thrombi, which had increased in size. The device and thrombotic material were surgically removed, and the defect was closed without complications. Histologic examination detected a marked foreign body reaction at the Dacron-tissue interface (Figure 2).

\section{Discussion}

At present, the CardioSEAL and Amplatzer (AGA Medical Corp, Golden Valley, Minn) occluders are approved under humanitarian device regulations by the US Food and Drug Administration for

\footnotetext{
From the Department of Cardiology and Intensive Care Medicine, LKHGraz-West, ${ }^{\mathrm{a}}$ Institute of Pathology, Medical University Graz, ${ }^{\mathrm{b}}$ and Department of Cardiac Surgery, Medical University Graz, ${ }^{c}$ Graz, Austria.

Received for publication Dec 16, 2004; accepted for publication Dec 21, 2004.

Address for reprints: Dr Herwig W Schuchlenz, Department of Cardiology and Intensive Care Medicine, LKH-Graz-West, A-8020 Graz, Austria (E-mail: herwig.schuchlenz@lkh-grazwest.at)

J Thorac Cardiovasc Surg 2005;130:591-2

$0022-5223 / \$ 30.00$

Copyright $\odot 2005$ by The American Association for Thoracic Surgery

doi:10.1016/j.jtcvs.2004.12.030
}

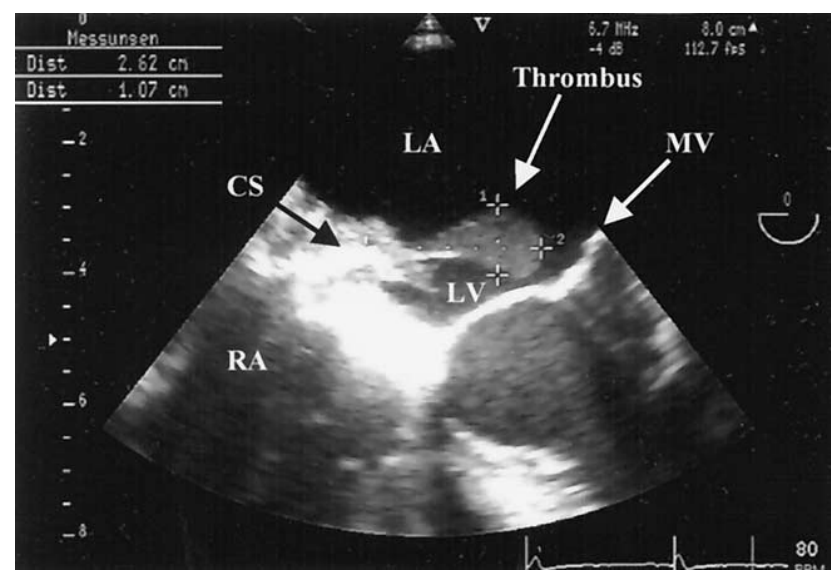

Figure 1. Transesophageal echocardiography 4-chamber view demonstrating a large mobile thrombus attached to the left atrial disc of the CardioSEAL (NMT Medical, Boston, Mass) occluder. $L A$, Left atrium; $R A$, right atrium; $L V$, left ventricle; $M V$, mitral valve; CS, CardioSEAL occluder.

PFO closure in patients who have had multiple strokes and in whom conventional drug therapy with warfarin has failed. The most commonly reported complications after percutaneous device implantation are atrial fibrillation in approximately $6 \%$ and thrombus formation on the device ranging from $7 \%$ to $22 \%$ in patients with the CardioSEAL device, compared with $0 \%$ in patients with the Amplatzer device. ${ }^{1,2}$ Device design may therefore have an impact on tissue reaction.

The CardioSEAL device consists of 2 sets of flexible metallic arms (alloy of nickel and titanium [nitinol]) to which polyester fabric (Dacron) is attached. The Amplatzer device is a selfcentering double disc made from nitinol wire frame filled with polyester fabric.

A fast endothelialization without thrombus formation or marked foreign body reaction is reported for both devices. However, histologic information about the tissue reaction after device implantation is limited to animal studies. ${ }^{3,4}$

Various in vitro and in vivo studies demonstrated that Dacron may generate a severe implant-host reaction that may induce thrombus formation or trigger atrial arrhythmias as reported in this case. $^{5}$

Although animal studies usually show uncomplicated tissue ingrowth and endothelialization after device implantation, our case documents that tissue reaction to the CardioSEAL occluder may be unpredictable in human hearts and may expose patients to a life-threatening situation. Further research should be focused on the application of more biocompatible materials to avoid the consequences of foreign body response. 


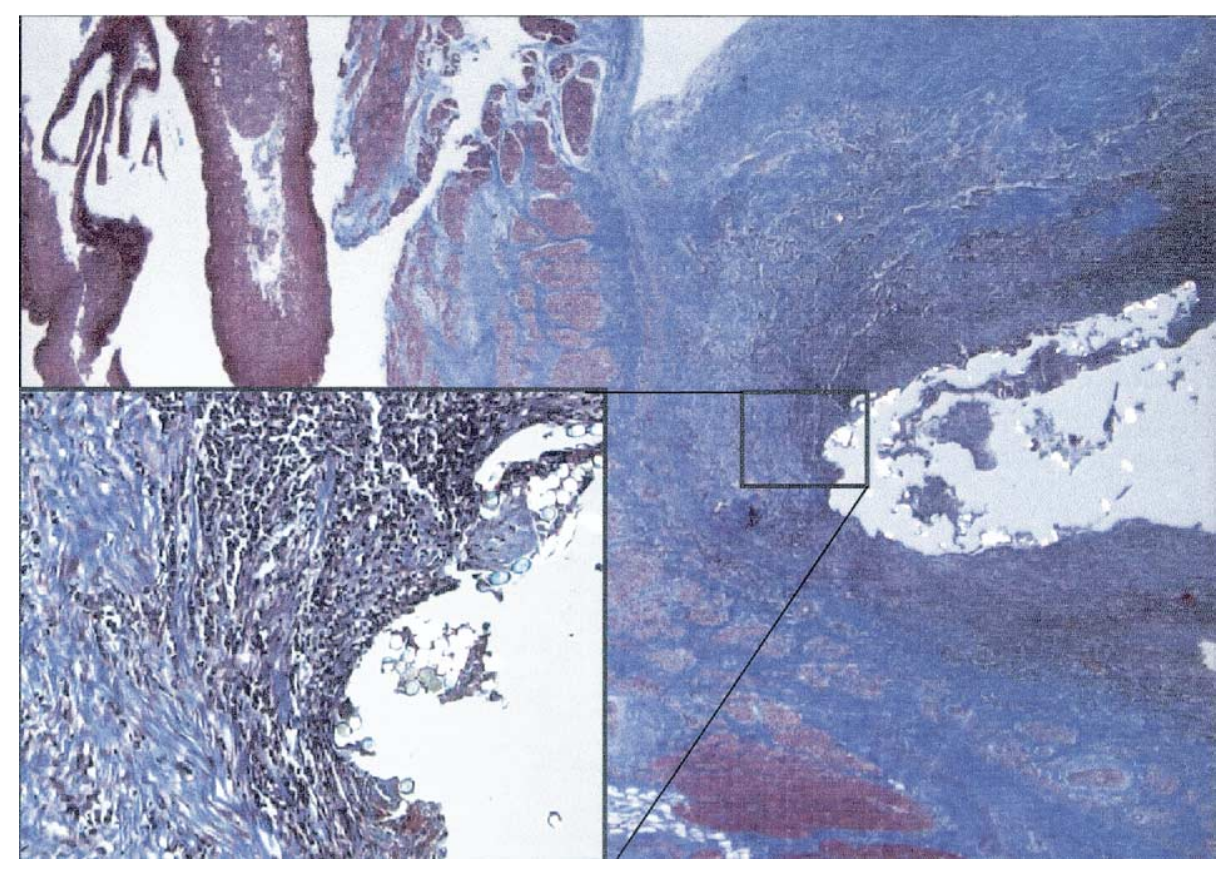

Figure 2. Microscopic examination showing a foreign body reaction with granulation tissue (right). Part of the thrombus $($ left) (magnification $\times 20)$. Higher magnification $(\times 200)$ of the granulation tissue with polarizing foreign material (inset) (stained with trichrome, collagen [blue]; muscle and thrombus [red]).

\section{References}

1. Krumsdorf U, Ostermayer S, Billinger K, Trepels T, Zadan E, Horvath $\mathrm{K}$, et al. Incidence and clinical course of thrombus formation on atrial septal defect and patent foramen ovale closure devices in 1000 consecutive patients. J Am Coll Cardiol. 2004;43:302-9.

2. Anzai H, Child J, Natterson B, Krivokapich J, Fishbein CM, Chan FK, et al. Incidence of thrombus formation on the CardioSeal and the Amplatzer interatrial closure devices. Am J Cardiol. 2004;93:426-31.
3. Kuhn MA, Latson LA, Cheatham JP, McManus B, Anderson JM, Kilzer $\mathrm{KM}$, et al. Biological response to Bard Clamshell septal occluders in the canine heart. Circulation. 1996;93:1459-63.

4. Lock JE, Rome JJ, Davis R, Van Praagh S, Perry SB, Van Praagh R, et al. Transcatheter closure of atrial septal defects. Experimental studies. Circulation. 1989;79:1091-9.

5. Paquay Y, deRuijter JE, van der Waerden J, Jansen J. Tissue reaction to Dacron velour and titanium fibre mesh used for anchorage of percutaneous devices. Biomaterials. 1996;17:1251-6. 